\title{
Inclusão financeira e desenvolvimento rural: A importância das organizações territoriais
}

\author{
Ademir Antonio Cazella* \\ Fábio Luiz Búrigo**
}

\section{Resumo}

Neste artigo são analisados os condicionantes para a construção de sistemas de financiamento de processos de desenvolvimento territorial sustentável em zonas rurais. Em particular, são avaliadas as possibilidades e os dilemas que se apresentam atualmente para a inclusão financeira de segmentos sociais empobrecidos e para aumentar a participação das organizações territoriais na gestão desses sistemas. Com base nesses dois pressupostos, o trabalho aborda duas experiências empíricas que demonstram avanços nessa direção: o Programa Crediamigo do Banco do Nordeste e o cooperativismo de crédito solidário presente na região sul do País. Conclui-se que os dois casos apresentam arranjos institucionais inovadores, que têm gerado resultados relevantes em relação ao volume de empréstimos, à área de abrangência, ao percentual de público atendido e aos sistemas de governança. Porém, ambos necessitam aprimorar suas formas de atuação caso desejem atender demandas de caráter intersetorial e focadas no desenvolvimento dos territórios em que atuam.

Palavras-chave: Desenvolvimento territorial sustentável; Inclusão financeira; Sistemas de governança

\section{Introdução}

objetivo principal deste artigo consiste em analisar os condicionantes para a construção de sistemas de financiamento de processos de Desenvolvimento Territorial Sustentável (DTS), especialmente voltados para o atendimento de regiões rurais brasileiras.

\footnotetext{
* Professor da UFSC, junto ao Programa de Pós-graduação em Agroecossistemas.

* Doutor em Sociologia Política (UFSC).
} 
Procura-se avaliar, em particular, as possibilidades e os dilemas que se apresentam para a inclusão financeira de segmentos sociais empobrecidos e para aumentar a participação das organizações territoriais na gestão desses sistemas. Uma investigação preliminar realizada pelos autores sobre o conjunto de organizações e arranjos institucionais existentes nesse setor revelou duas experiências que atendem parcialmente esses propósitos ${ }^{1}$. Tratam-se das ações de microcrédito empreendidas pelo Banco do Nordeste (BN) e das atividades microfinanceiras desenvolvidas pelo cooperativismo de crédito rural solidário, capitaneadas pela Associação Nacional das Cooperativas de Crédito de Economia Familiar e Solidária (Ancosol).

Essas duas iniciativas, além de consolidadas - pois romperam os limites dos chamados projetos pilotos-, apresentam um conjunto de inovações, especialmente na formação de seus arranjos institucionais e nos mecanismos de governança. Tais avanços refletem-se no grande número de beneficiados diretos, volume de recursos financeiros mobilizados, interface com políticas públicas, consistência institucional, área de abrangência e, não menos importante, prédisposição de seus gestores para adoção dos preceitos do DTS.

O trabalho procura demonstrar, também, que as duas experiências apresentam formas inéditas no sentido de ampliar-se a escala de projetos estratégicos de desenvolvimento territorial sustentável, rompendo os limites dos chamados "arquipélagos desarticulados" de ações dessa natureza ${ }^{2}$. Por distintos aspectos, ambas servem, portanto, de referência para a deflagração de iniciativas similares, tanto em territórios onde se deseja ampliar a qualidade dos produtos e das organizações financeiras existentes, quanto em regiões "pioneiras”, isto é, zonas que não possuem serviços dessa natureza.

1 Este estudo integra um projeto de pesquisa sobre a geração de novas políticas de desenvolvimento territorial no Brasil que está sendo realizado pela equipe do Observatório de Políticas Públicas para a Agricultura (OPPA - CPDA - UFRRJ), com apoio do Instituto Interamericano de Cooperação para a Agricultura (IICA). Para os primeiros resultados referentes ao tema "Sistemas de financiamento do desenvolvimento territorial”. ver Cazella e Búrigo (2008a).

2 Para Ignacy Sachs, em palestra proferida durante o III Fórum internacional de modelos e instrumentos para gestão social dos territórios organizado pelo IICA entre os dias 05 e 07/11/2008 na cidade de Fortaleza (CE), as ações de DTS precisam romper a barreira de projetos pilotos e ampliar sua escala e impactos. 
O artigo está subdividido em três partes principais, além desta introdução. A primeira apresenta uma reflexão teórica sobre o tema das microcrofinanças, tido aqui como política de base para a instauração de dinâmicas de DTS. A segunda analisa o Programa Crediamigo do Banco do Nordeste e o Sistema Cresol, identificado como a experiência de cooperativismo de crédito rural mais consolidada dentro da rede Ancosol. Por fim, a título de conclusão, um conjunto de proposições é elencado, visando à superação, de um lado, da predominância de linhas de financiamento baseadas em produtos ou em atividades de caráter setorial, e de outro, da tendência de fuga de recursos financeiros dos territórios rurais, especialmente daqueles mais isolados do ponto de vista geográfico e econômico.

\section{Pobreza rural e acesso ao crédito}

No meio rural brasileiro, um contingente expressivo de atores empobrecidos não integra o público prioritário das principais agências do Estado, ONG, organizações profissionais agrícolas e movimentos sociais e sindicais, que atuam na concepção e captação de recursos financeiros para projetos de desenvolvimento. Dessa forma, a ampla maioria desses projetos acaba priorizando atores que reúnem melhores condições sociotécnicas, políticas e econômicas para empreender no meio rural (CAZELLA, 2006).

Esse quadro exige que se supere a visão predominante de que o meio rural brasileiro encontra-se dividido entre agricultores familiares empobrecidos versus agricultores patronais bem integrados nos mercados e, em especial, privilegiados pelas políticas agrícolas. Não só no interior da agricultura familiar persiste um contingente expressivo de famílias rurais invisíveis aos olhos dos diferentes organismos de desenvolvimento, como também se desconhece o tamanho e as estratégias de vida de assalariados sazonais, diaristas, empreiteiros e de uma gama de microempreendedores, que se reproduzem socialmente à margem de qualquer política ou iniciativa formal de desenvolvimento rural.

Além disso, a compreensão de que a socioeconomia de serviços financeiros territorializados e o desenvolvimento territorial sustentável são dois corpus indissociáveis ainda encontra-se em 
fase embrionária no Brasil. Na maioria das regiões rurais pouco se avançou na elaboração e aplicação de projetos articulados, que não disponibilizem crédito apenas para as atividades agropecuárias, mas contemplem também as demais iniciativas empreendidas por atores rurais diversos em outros setores da economia (CAZELLA \& BÚRIGO, 2008b e 2009; BONNAL \& PIRAUX, 2009).

A essas debilidades soma-se o perfil do Sistema Financeiro Nacional (SFN), que provoca uma constante fuga de capitais gerados na maior parte das regiões rurais, especialmente daquelas que se encontram fora da área de interesse dos grandes complexos agroindustriais. Muitas dessas zonas convivem com uma espécie de círculo vicioso, em que a ausência de organizações financeiras regionais aumenta a sua dependência econômica em relação aos pólos urbanos. A evasão das riquezas produzidas localmente aprofunda o ambiente de escassez de ideias e de projetos inovadores, assentados nos preceitos da sustentabilidade e do desenvolvimento territorial. Perpetuam-se, assim, as desigualdades regionais e o sentimento de dependência, minorados constantemente pela ação de políticas compensatórias, de cunho paternalista e de origem externa.

As políticas públicas relacionadas ao financiamento do DTS defrontam-se, também, com duas tendências verificadas no cenário mundial: i) a concentração bancária e a globalização dos mercados financeiros; ii) as estratégias comerciais dos bancos que, tradicionalmente, preferem atuar junto aos maiores aglomerados urbanos, oferecendo serviços aos clientes de grande e médio porte econômico. No caso brasileiro, mesmo dispondo de um mercado bancário extremamente sofisticado, a concentração bancária e, consequentemente, as lacunas em termos de atendimento financeiro são notórias. Em 1995, a relação entre crédito e Produto Interno Bruto (PIB) estava próxima de 0,35 . Em 2002, ela tinha caído para 0,24 , voltando a crescer para 0,31 em 2005 e 0,41 em 2008. Ou seja, nesse último ano, a oferta de recursos bancários para empréstimos foi da ordem de $41 \%$ do PIB. Em países desenvolvidos, esse número ultrapassa a $100 \%$.

No que se refere à concentração bancária, no final de 1996, os vinte maiores bancos brasileiros detinham $72 \%$ dos ativos totais do segmento bancário; os dez maiores bancos possuíam 60,1\%; e os cinco maiores bancos ficavam com $48,7 \%$. No final de 2004 , essa 
distribuição era respectivamente de 83,2\%, 68\% e 53\% (BÚRIGO, 2006). É improvável que nos últimos anos tenham ocorrido melhorias significativas nesse campo. Ao contrário, a recente fusão do Itaú e do Unibanco, a compra de bancos menores pelo Banco do Brasil (Nossa Caixa, metade do Banco Votorantim e de alguns bancos estaduais), além da crise financeira que abalou todos os países neste final de década, apontam para um aprofundamento desse processo. A centralização financeira afeta diretamente a distribuição dos empréstimos bancários: no final de 1994, os cinco maiores bancos brasileiros respondiam por $56,8 \%$ da oferta de crédito. Em dezembro de 2008 , esse porcentual havia aumentado para $77,5 \%$ (AUSTIN RAUTIN, 2009).

Apesar do recente esforço do Governo Federal, visando ampliar o acesso ao crédito e facilitar a abertura de contas simplificadas para as populações de baixa renda, muitos serviços financeiros estão ainda distantes de milhões de brasileiros. A exclusão está presente em todas as regiões, mas afeta, em especial, os territórios rurais menos desenvolvidos e distantes dos principais pólos econômicos. Nota-se que a simplicidade dos serviços e produtos disponíveis normalmente não atende as necessidades dessas regiões sob o prisma do desenvolvimento e nem significam um processo de inclusão financeira. Isto é, a oferta de serviços financeiros resume-se à possibilidade de dispor de uma conta bancária simplificada ou de uma linha de crédito que, muitas vezes, não contemplam as pessoas que mais precisam desses recursos. Além disso, a captação e o redirecionamento da poupança local, fonte de contrapartida e de sustentabilidade de projetos de médio e longo prazo, não são encarados como condição necessária para o desenvolvimento territorial sustentável.

Uma pesquisa sobre esse tema coordenada por Abramovay (2004) demonstra que em várias localidades brasileiras são limitações institucionais que excluem os mini e micro-poupadores e não a sua falta de interesse ou incapacidade de empreender e inovar. $\mathrm{Na}$ agricultura, muitas vezes, a frequiência desses fatos impede que agricultores pobres acumulem rendas suficientes para galgar outro estágio social e econômico. Na falta desses serviços, eles acabam investindo suas eventuais economias na compra de animais, terras 
ou itens de consumo, como eletrodomésticos e outros utensílios. A ausência de serviços financeiros coletivos, baratos e impessoais, dificulta o planejamento das atividades econômicas e a organização da vida financeira doméstica dos pobres (MAGALHÃES, 2003). Isso ocorre, por exemplo, quando eles têm necessidade de vender parte de seus ativos: por estar em forma não monetária e não fracionária, a falta de liquidez de sua poupança pode gerar situações pouco vantajosas (é preciso vender o animal por inteiro, por exemplo).

Esse tipo de situação faz com que essas famílias sofram considerável influência de laços monetários informais, muitos dos quais são ainda pouco conhecidos ou estudados. Embora esses laços possam traduzir-se em mecanismos de solidaridade e auto-ajuda financeira, assumindo, portanto, um valor positivo na sobrevivência das famílias, são também espaços para a proliferação de sistemas de extorsão e de agiotagem. Por sua vez, quando os pobres são assalariados, o que se vê é a presença constante de elevados níveis de endividamento. Para muitas famílias, a garantia salarial estimula as aquisições a prazo, mas as compras em demasia e os encargos financeiros acabam comprometendo uma boa parte de sua renda futura.

A investigação de Ferrary (2003) revela também como as avaliações sobre os riscos existentes nas operações de crédito, efetuadas por alguns bancos, incorporaram critérios de natureza subjetiva. Nesses casos, a experiência dos emprestadores e o conhecimento a respeito da situação de cada tomador contam muito. Ainda assim, mesmo que se tenham as melhores informações sobre os rumos da economia e sobre quais serão os seus impactos sobre os financiamentos, é impossível conhecer com exatidão a situação financeira e as intenções dos tomadores ou o que vai ocorrer durante o período do contrato. Essa assimetria de informações, que se move do campo das intenções para o da capacidade de prever-se uma situação futura, leva ao aprofundamento da seleção adversa. Ou seja, as organizações financeiras acabam eliminando uma parte potencial de sua clientela decorrente da falta do conhecimento pleno, seja da idoneidade do tomador do crédito, seja da viabilidade dos seus negócios.

A consequiência da aversão ao risco dos sistemas financeiros tradicionais é que os serviços de crédito ficam circunscritos a número menor de clientes. São selecionados aqueles que suportam pagar 
as taxas e as tarifas estabelecidas, os que têm maiores somas de depósitos (reciprocidade) e os que oferecem maiores garantias em seus pleitos. Isso demonstra que a exclusão bancária e a consequiente criação de sistemas informais são reflexos do mesmo conjunto de fatores que existem no mercado de crédito.

A resistência à maior participação dos pobres no sistema bancário começou a ser revista nas últimas décadas do século XX, com a difusão do microcrédito e das Organizações Microfinanceiras (OMF). Algumas OMF criaram formas inovadoras de combater a pobreza com a ajuda de recursos financeiros. Em primeiro lugar, elas conseguiram atingir um grande número de clientes com serviços financeiros de pequena monta, indicando que o interesse das pessoas pobres de relacionar-se com uma fonte de liquidez monetária existe e não é eventual. Em segundo, os custos do seu trabalho foram cobertos pela combinação de baixas taxas de inadimplência com maneiras inéditas de reduzir as despesas operacionais.

O baixo número de maus pagadores devia-se, em parte, à intervenção de funcionários tecnicamente preparados, que visitavam os clientes periodicamente e conheciam mais claramente os seus potenciais e seus limites enquanto empreendedores. Os custos de transação e a falta de garantias para a liberação de empréstimos eram, normalmente, supridos por sistemas de aval solidário (garantias cruzadas) e por taxas de juros semelhantes às praticadas pelo mercado bancário, porém inferiores as cobradas pelos agiotas (BÚRIGO, 2006). Em outras palavras, a onda do microcrédito provocou um ineditismo operacional no meio financeiro que pode ser assim traduzido: uso concomitante de agentes de crédito, garantias do tipo solidário e contratos com prazos curtos e valores crescentes (MORDUCH, 2000; DARCY \& SOARES, 2004).

Em 2002, um encontro de especialistas mundiais em microcrédito e microfinanças elencaram os elementos necessários para implantarem-se serviços consistentes de crédito no atendimento de populações pobres e que vivem em zonas "difíceis". Os mais importantes são os seguintes: 1) a existência de uma gama de serviços flexíveis e adaptados. Isso pode dar-se, por exemplo, por meio da presença de pontos de atendimento ou de profissionais nos locais 
de maior concentração de negócios ${ }^{3}$. São também relevantes, nesse sentido, as iniciativas que buscam combinar a poupança obrigatória e a do tipo voluntária com projetos que estimulem a formação de grupos de poupadores; 2) as subvenções cruzadas (fundamentais para viabilizar a carteira $)^{4}$; 3) a limitação dos custos de pessoal (através do recrutamento local e com gente de mesmo nível socioeconômico); e 4) o apoio na intermediação de redes sociais, como forma de reduzir os custos de transação e ampliar o alcance do programa (HIRSCHLAND, 2003).

Para o Comitê de Trocas, Reflexão e Informação sobre os Sistemas de Poupança e Crédito (Cerise), criado por organizações européias que atuam na área das microfinanças e das finanças solidárias, a governança de uma organização de microfinanças apóia-se na estrutura de propriedade, associada ao conjunto dos mecanismos pelos quais os dirigentes eleitos, funcionários e outros definirão e executarão a sua missão (notadamente a escolha do público alvo, os serviços e a cobertura geográfica) e assegurarão a perenidade, a adaptação ao ambiente, a prevenção e as soluções para as crises.

No Brasil, embora já existissem projetos localizados de microcrédito desde os anos 1970, a sua expansão em maior escala tem sido tardia, tornando-se mais visível somente na década de 1990. Além da lenta difusão, o microcrédito brasileiro assumiu diversos formatos institucionais. Depois de anos de debates e de ter-se constatado que algumas iniciativas públicas e privadas mostravam-se incipientes diante das necessidades do país nessa área, em 2005 o Governo Federal criou o Programa Nacional de Microcrédito Produtivo e Orientado (PNMPO). Além de alocar recursos públicos, o PNMPO estabeleceu novas regras para o funcionamento do setor.

3 Em alguns países é comum a existência de banqueiros ambulantes e outros profissionais especializados em oferecer atividades microfinanceiras diretamente nas ruas. Esses agentes coletam os recursos monetários e prestam outros serviços financeiros para os pequenos comerciantes e empreendedores que não possuem condições de se deslocar com frequiência até um ponto de atendimento bancário.

4 Aplicação combinada dos resultados financeiros obtidos nas carteiras de empréstimos e nas carteiras de depósitos. Assim, as rendas obtidas nos serviços de (micro) empréstimos podem auxiliar na oferta e na extensão dos serviços ligados aos (micro) depósitos. 
Dados do Banco Central indicam que, no final de 2007, havia cerca de 230 organizações atuando regularmente no microcrédito no Brasil, sendo o formato jurídico dessas organizações muito variado: ONG, Organização da Sociedade Civil de Interesse Público (Oscip), Sociedades de Crédito ao Micro-empreendedor (SCM) e à Empresa de Pequeno Porte, bancos privados e agentes governamentais. Tal universo manejava uma carteira de $\mathrm{R} \$ 1,2$ bilhão, o que representava uma penetração de apenas $16 \%$ do mercado potencial, estimado em R\$ 12 bilhões. Entre 2006 e 2007, o número de clientes ativos de microcrédito no Brasil saltou de 690 mil para 1,1 milhão. A quase duplicação dos beneficários em apenas um ano pode significar que as medidas lançadas pelo PNMPO começaram a apresentar seus primeiros resultados, muito embora o número de atendidos esteja ainda aquém do indicado pelos estudos que avaliam o potencial do setor das microfinanças no país. Estima-se a existência de cerca de dezesseis milhões de pequenas unidades produtivas geridas, em boa parte, pelos treze milhões de trabalhadores que atuam por conta própria. Desses, sete milhões podem ser considerados demandantes potenciais de microcrédito (SOARES \& MELO SOBRINHO, 2008).

Essa defasagem entre serviços ofertados e clientela potencial de microcrédito instiga à compreensão de experiências consideradas exitosas nessa área. Na sequiência, o estudo passa à análise das virtudes e limitações do Crediamigo e do Sistema Cresol, com vistas a avançar na reflexão de novos caminhos para a inclusão financeira e sua articulação com iniciativas de DTS no Brasil.

\section{Duas experiências relevantes de microfinanças no Brasil}

\subsection{O Programa Crediamigo do Banco do Nordeste}

A atuação do Banco do Nordeste dá-se, fundamentalmente, na área de abrangência da Superintendência para o Desenvolvimento do Nordeste (Sudene) - nove estados nordestinos, norte de Minas Gerais e nordeste do Espírito Santo -, mais o Distrito Federal. A origem do Programa Crediamigo está associada ao processo de estabilização da economia deflagrada com o Plano Real em meados dos 
anos 1990 e à conseqüiente necessidade dos bancos em criar novos produtos e serviços. A experiência bem sucedida do programa de crédito para a população de renda baixa de Bangladesh (Grameen Bank $)^{5}$ serviu de inspiração para a concepção, em 1998, do Programa de Microcrédito Crediamigo.

Dentre as principais características do Crediamigo encontramse os seguintes mecanismos operacionais e de gestão: a figura dos "agentes de crédito", a adoção de sistemas de aval solidário, a implantação de serviços de orientação aos empreendedores de baixa renda, a animação de fóruns de discussão municipais denominado de "Farol do Desenvolvimento", o Crediamigo Comunidade (Village Bank), o Agroamigo e a parceria com o Instituto Nordeste Cidadania (INEC).

Esse conjunto coordenado de mecanismos explica o fato de o Crediamigo ser hoje o segundo maior programa de microcrédito existente na América Latina e Caribe. As lições positivas obtidas na gestão desse tipo de crédito, inicialmente circunscritas no meio urbano, estão sendo, aos poucos, transferidas para o meio rural. É o caso do Agroamigo, que se volta para a aplicação da modalidade denominada "Grupo B" do Programa Nacional de Fortalecimento da Agricultura Familiar (Pronaf B) ${ }^{6}$, e do Crediamigo Comunidade. Além disso, se é verdade que uma parcela importante dos clientes do Programa Crediamigo habita em aglomerações metropolitanas, diversos microempreendedores de pequenos municípios do interior nordestino atendidos pelo Programa representam uma categoria de

5 O Banco do Nordeste não se limitou a se espelhar no sucesso dessa experiência, cujos resultados e reconhecimento internacional justificam a atribuição do Prêmio Nobel da Paz de 2006 ao seu principal idealizador (Muhammad Yunus). Outras iniciativas de microcrédito foram consideradas, a exemplo do Banco Rakyat (Indonésia), Banestado e Banco de Desarollo (Chile), Finasol (Colômbia) e BancoSol e Caja de los Andes (Bolívia).

6 Linha de crédito do Pronaf que beneficia agricultores familiares de baixa renda: faturamento bruto anual inferior a $\mathrm{R} \$ 4.000,00$, excluídas as rendas de programas sociais públicos. O teto máximo do empréstimo anual chega a $\mathrm{R} \$ 1.500,00$, com carência de até dois anos, taxa de juro anual de 0,5\% e bônus de adimplência de $25 \%$ do valor principal e dos juros. Apesar do forte subsídio, essa linha do Pronaf apresenta altos índices de inadimplência, sobretudo no Nordeste, decorrentes da falta de medidas de gestão especiais junto aos agricultores tomadores desse tipo de crédito. 
atores sociais e econômicos que diversificam e enriquecem as teias socioeconômicas dos territórios rurais.

A iniciativa recente do Banco do Nordeste de estender sua experiência de microcrédito para o meio agrícola por meio do lançamento do Programa Agroamigo tem por objetivo aprimorar o processo de gestão da modalidade do Pronaf $\mathrm{B}$, que tem registrado em muitos municípios nordestinos o alarmante índice de $30 \%$ de inadimplência. A análise desse tema realizada por Abramovay (2008, p.18) demonstra que essa situação não é decorrente de calamidades naturais, a exemplo de estiagens recorrentes na região, mas da difusão, "por parte de organizações locais, da mensagem de que os créditos serão renegociados e que, portanto, não vale a pena honrar os compromissos assumidos".

Depois de três anos de atuação do BN nessa modalidade de crédito, aplicando a metodologia de gestão do Crediamigo, a inadimplência do Pronaf B caiu para a casa dos 3,2\%. "A grande novidade do Agroamigo é que os financiamentos passam a ser geridos por um assessor de crédito, responsável por uma carteira de projetos e que estabelece uma relação personalizada com cada agricultor beneficiário do Programa” (ABRAMOVAY, 2008, p.24).

Outra ferramenta do Crediamigo que começa a ser difundida nas zonas rurais, após ter sido testado em zonas urbanas, é o Crediamigo Comunidade, inspirado na idéia de Village Bank, ou banco da comunidade. Como explica Abramovay (2008), essa modalidade do Crediamigo agrupa entre quinze e trinta pessoas de uma comunidade, que participam de uma mesma conta poupança gerida por três membros do grupo, além de disporem de contas bancárias simplificadas. Outra especificidade que diferencia essa modalidade das demais regras e serviços prestados pelo Programa é a permissão para admitir a integração de pessoas com pendências junto aos serviços de proteção ao crédito, decorrentes de pequenas dívidas não-bancárias e a possibilidade de atender empreendedores que possuam menos de um ano de experiência no ramo que deseja financiar. A maior parte dos financiamentos do programa volta-se para pessoas que atuam há mais de um ano no seu ramo de negócio, não contemplando, portanto, aqueles que desejam iniciar uma nova atividade. Até dezembro de 2007, 
o Crediamigo Comunidade dispunha de 1.145 "bancos", vinte mil clientes e R\$ 5,6 milhões de carteira ativa.

A experiência do Crediamigo Comunidade torna-se especialmente importante para quem deseja fomentar a constituição de organizações financeiras de base cooperativa ou ampliar a "proximidade" entre os sistemas financeiros e as comunidades. O conceito das finanças de proximidade

parte da tese de que as relações entre as organizações financeiras e o seu público devam apresentar um elevado grau de aproximação, que não é somente geográfico, mas é também administrativo, cultural e político. Para atuar numa lógica das finanças de proximidade, os agentes financeiros devem, no aspecto espacial, se localizar próximo de onde vivem os beneficiários; no aspecto social, se preocupar com o atendimento das necessidades financeiras de interesse da comunidade; no aspecto gerencial, criar estruturas de decisão democráticas e participativas (BÚRIGO, 2006, p.39-40) ${ }^{7}$.

Depois de alguns anos de funcionamento dentro da estrutura do Banco, atualmente composta por 170 agências e 53 postos de atendimentos, o Crediamigo conta com uma estrutura própria de gestão. Para isso, o BN firmou um convênio, no final de 2003, com o INEC, uma Oscip criada pelos funcionários do Banco em 1993. O objetivo principal dessa parceria consiste na diminuição dos custos operacionais do Programa, além de aprimorar as condições de gestão por meio da disponibilidade de um quadro de colaboradores especializados em operações de microcrédito.

O foco no público de baixa renda condiz com os valores dos empréstimos realizados, que podem variar de $\mathrm{R} \$ 100,00$ a $\mathrm{R} \$ 10.000,00$, seja como capital de giro, seja como investimento fixo. $O$ endividamento máximo permitido é do teto para capital de giro e de $\mathrm{R} \$ 5.000,00$ para investimento. As taxas de juros mensais também dependem do tipo de operação. Para capital de giro com valores inferiores a mil reais incide $1,95 \%$ ao mês (a.m.) e para as operações superiores a essa soma os custos se elevam para 2 a 3\%

7 Sobre a importância dos sistemas financeiros de proximidade ver, também, Servet; Vallat (2001) e Abramovay (2003a). 
a.m. Já para os contratos de investimento fixo, a taxa de juros é de 2,95\% a.m. Nos empréstimos para capital de giro, os prazos para reembolso variam de um a seis meses e, nos contratos de investimento fixo, chegam a 36 meses, sem carência.

A inexistência de período de carência para iniciar o pagamento explica, em parte, o fato das operações financiadas só considerarem os micro-empreendimentos (formais e informais) que já estejam em atividade há pelo menos um ano. Mas é nos custos dos empréstimos que reside um aspecto importante do Crediamigo: não existe nenhum tipo de subsídio aportado pelo banco. Embora no início tenha recebido ajudas do Banco Mundial, atualmente o programa não ganha nenhum aporte financeiro direto para se manter em funcionamento, seja do próprio banco, seja de outros agentes. A explicação para os bons resultados está, portanto, na adoção de sistemas de governança inéditos no SFN e na adaptação bem sucedida de técnicas de gestão de carteiras de microcrédito já testadas em outras experiências consagradas nessa área.

Até agosto de 2008, o Crediamigo tinha 352 mil clientes, tendo por meta atingir um milhão até 2011. As estimativas feitas por Neri (2008) sobre o mercado potencial de microcrédito no Nordeste são de 4,6 milhões de trabalhadores por conta própria e empregadores, excetuando os empreendimentos agropecuários. Percebe-se, assim, que o Crediamigo contemplou até agosto de 2008 quase $8 \%$ da clientela potencial de microcrédito existente na região.

Entre o final de 2003 e meados de 2008, a carteira ativa do Crediamigo, que considera os valores dos contratos em vigência normal ou em atraso de até noventa dias, subiu de R\$ 85 milhões para $\mathrm{R} \$ 277,3$ milhões. O valor total desembolsado aos clientes passou de R\$ 368 milhões em 2003 para R\$ 794,2 milhões em 2007. Ademais, as médias das operações também aumentaram no período, passando de $\mathrm{R} \$ 847,00$ para $\mathrm{R} \$ 1.030,00$.

Nas normas do Crediamigo considera-se como inadimplente o tomador de crédito que atrasar o pagamento a partir de um dia. A inadimplência caiu de 2,09\% em 2002 para menos de $1 \%$ a partir de 2004, índice que se manteve nos anos subsequientes. A excelente taxa de retorno dos valores emprestados está diretamente associada ao seu sistema de gestão. Sua estrutura operacional não se encontra 
assentada de forma exclusiva, nem nas agências e postos do BN, nem no quadro de pessoal do banco. Nos pontos de atendimentos diversos, a exemplo de sedes de prefeituras, sindicatos, Emater e Correios, a figura do "assessor de crédito" representa o pilar da tecnologia de microcrédito. A proximidade e o conhecimento interpessoal entre o tomador de crédito e o assessor explicam, em grande parte, os resultados positivos.

Como aponta Abramovay (2008, p.25), "é claro que a proximidade pode abrir caminho igualmente a empréstimos realizados de maneira inadequada e pouco criteriosa, por razões familiares ou de amizades". No entanto, o rigor gerencial do programa permite identificar e punir aqueles assessores que não adotam os preceitos operacionais que lhes são repassados de forma sistemática nas ações de capacitação. Além disso, a vinculação de parte da remuneração desses agentes aos resultados de adimplência e do tamanho da sua carteira de crédito reforça o compromisso mútuo e os laços de solidariedade entre assessor e beneficiado.

Outro elemento que integra a engenharia de gestão e que certamente tem um peso explicativo importante para os elevados índices de adimplência do Crediamigo é a intenção deliberada de privilegiar a participação da mulher nas tomadas de empréstimos. Nada menos que $64 \%$ das operações de microcrédito são efetuadas por mulheres. A maior assiduidade nos pagamentos efetuados pelo público feminino é uma das características que chama atenção nos programas de microcrédito em todo o mundo. Essa orientação não é uma inovação da experiência brasileira, mas a adoção de uma das lições que estão na origem do Grameen Bank. Yunus e Jolis (2003) dedicam três capítulos exclusivos do seu livro a essa temática ${ }^{8}$, além de constantes referências e exemplos sobre a importância de se considerar de forma contundente a questão de gênero na concepção de sistemas de microfinanciamentos. Em Blangadesh, as mulheres eram responsáveis por menos de $1 \%$ dos empréstimos concedidos pelos bancos. Na fase experimental do Grameen foi fixada a cota de

8 Tratam-se dos capítulos "Por que emprestar dinheiro às mulheres, de preferência aos homens?"; "O primeiro contato com as financiadas (ocultas pelo purdah)" e "Ser mulher e trabalhar para o Grameen". 
$50 \%$ de empréstimos para mulheres, sendo que na atualidade esse índice chega a $94 \%$ (Neri, 2008).

No Brasil, os esforços explícitos de inclusão do universo feminino nas operações de microcrédito ainda figuram como casos isolados. A situação mais notória nessa área refere-se ao Pronaf. Após mais de doze anos de existência desse programa de crédito rural, a participação da mulher é pífia inclusive no interior de iniciativas levadas a cabo por organizações representativas da agricultura familiar. O estudo de Fernandes (2008) revela que mesmo o movimento de cooperativismo de crédito solidário difundido nos últimos quinze anos no sul do país não tem dado a devida atenção a esse tema. A linha de crédito denominada Pronaf Mulher registra um número de contratos insignificantes no cômputo geral do Programa.

A avaliação efetuada por Neri (2008, p.303) sobre os benefícios econômicos que o Programa Crediamigo propiciou nos negócios dos clientes revela que a maioria melhorou de forma considerável sua renda. "A probabilidade de um cliente ultrapassar as linhas de pobreza especificadas aumenta consideravelmente a cada seis meses, quando ele se mantém como cliente ativo. Aqueles indivíduos com mais de cinco anos no programa têm uma probabilidade maior de deixar essa situação (...)". No entanto, outra constatação efetuada por esse autor encontra-se no fato do Crediamigo não contemplar entre a sua clientela a porção mais pobre dentre os pobres, residindo aí um aspecto limitante a ser superado. Além disso, o programa ainda não tem uma clara orientação no sentido de aprofundar sua atuação no meio rural e menos ainda de buscar uma inserção territorial explícita, por meio de parcerias com os fóruns territoriais existentes. O estudo a seguir, da experiência do cooperativismo de crédito solidário, além de contemplar uma região geográfica distinta, aporta a especificidade de se tratar de uma intervenção essencialmente rural.

\subsection{O Cooperativismo de Crédito Solidário}

Vários autores sugerem que o cooperativismo de crédito seja a referência mais promissora para se popularizar as finanças no meio rural brasileiro (CAZELLA, 2002; ABRAMOVAY, 2003b; BITTENCOURT, 
2003; BÚRIGO, 2006). Além de ser uma sociedade de pessoas e não de capital, a cooperativa de crédito é a única organização legalmente autorizada (além dos bancos) a captar depósitos (poupança) - um dos instrumentos chaves para se dinamizar a economia local.

As regras que orientam o funcionamento das cooperativas de crédito favorecem a organização financeira de proximidade. Por vezes, fatores de natureza extra-econômica permitem também que essas organizações pratiquem taxas competitivas nos seus serviços de crédito e que têm, não raramente, o papel regulatório no mercado financeiro local. Além disso, a existência dessas cooperativas facilita a organização dos financiamentos "quentes", que são assim denominados por serem realizados com recursos da própria comunidade (BÉDARD, 1986). Ao contrário dos recursos "frios", obtidos via fontes externas, os primeiros tornam os membros da comunidade mais vigilantes e preocupados com a sua aplicação, pois seu mau uso trará consequiências diretas para eles próprios (os associados depositantes).

Embora sua presença venha aumentando nas últimas décadas, nota-se que o peso econômico das cooperativas de crédito ainda não é significativo dentro do mercado financeiro nacional. Em dezembro de 2007, as 1.462 cooperativas de crédito brasileiras e seus 2.621 Postos de Atendimento Cooperativo (PAC) atendiam somente 3,5 milhões de associados. Juntas, essas organizações eram responsáveis por $1,3 \%$ dos depósitos e $2,1 \%$ das operações de crédito do segmento bancário ${ }^{9}$. Esses indicadores estão bem aquém do que se observa na grande maioria das regiões do mundo - a taxa de crescimento do setor dentro do mercado bancário nacional é superior apenas ao encontrado em países da Oceania e Ásia Central. Existe também uma profunda desigualdade no interior do país em relação à incidência do cooperativismo de crédito. Em 2007, as cooperativas de crédito da região Sul foram responsáveis por 5,6\% dos depósitos e 5,3\% das operações de crédito realizados no âmbito do Sistema Financeiro Nacional, enquanto no Nordeste

9 O Banco Central contempla na "área bancária” os bancos múltiplos, comerciais, Banco do Brasil, Caixa Econômica Estadual e Federal, os bancos de desenvolvimento e as cooperativas de crédito. 
essa participação foi, respectivamente, de $1,2 \%$ e $0,7 \%$ (SOARES \& MELO SOBRINHO, 2008).

A existência de vários sistemas cooperativistas de crédito no Brasil revela distintas inspirações e diferenças em termos de concepção ideológica, arranjos institucionais e modelos gerenciais. Dos quatro maiores sistemas, três são baseados em estruturas cooperativas próximas de uma cultura bancária, pois norteiam sua atuação numa lógica de profissionalização gerencial e concentração de recursos, visando ganhos de escala. Assim como em grande parte do cooperativismo de crédito mundial, esses sistemas são controlados e voltam-se para camadas da classe média da população, tendo pouca inserção nos extratos de menor renda. Dois deles, o Sistema de Cooperativas de Crédito do Brasil (Sicoob) e o Sistema de Crédito Cooperativo (Sicredi), atuam com um público urbano e rural diversificado, enquanto o terceiro, o Sistema Unicred Brasil (Unicred), está ligado aos profissionais da área da saúde.

Paralelo a esses três grandes sistemas, ganhou força nos últimos anos a Rede Ancosol. A Associação Ancosol foi legalmente constituída em 2004 com o objetivo de articular, integrar e representar as organizações do cooperativismo de crédito de economia familiar e solidária que emergiram no Brasil a partir dos anos 1990. Esse movimento representa a consolidação de um novo modo de funcionamento de cooperativas, denominada por Pinho (2004) de "vertente solidária". Trata-se de uma concepção que não se preocupa apenas em obter benefícios econômicos e expandir seu capital, mas procura estender a sua ação ao máximo de pessoas que integram sua base de ação, como também fortalecer seus afiliados em outras dimensões (social, cultural, ambiental, política etc.). As cooperativas de caráter solidário buscam, portanto, uma forte integração na realidade local para alcançar e manter sua legitimidade e dar cumprimento a sua missão estratégica dentro dos princípios universais do cooperativismo (BÚRIGO, 2006).

Atualmente, a organização integrante de maior destaque da Rede Ancosol, e que está servindo de modelo para a estruturação de outras estruturas de cooperativas de crédito solidárias no Brasil, é o Sistema das Cooperativas de Crédito Rural com Interação 
Solidária (Cresol) ${ }^{10}$. Com treze anos de funcionamento, o Sistema Cresol ocupa a quarta posição dentro do cenário do cooperativismo de crédito nacional, estando já presente em quase quinhentos municípios dos três estados do Sul. Grande parte dos atendimentos prestados pela Cresol ocorre em zonas tipicamente rurais. Ou seja, municípios que possuem menos de vinte mil habitantes contam com forte presença de atividades agrícolas e reúnem uma população rural superior à média da região Sul.

Ao contrário do que se vê em muitos sistemas cooperativistas que alcançaram bons resultados financeiros, na Cresol o sucesso econômico não significou um distanciamento da cúpula de gestores em relação à sua base social. Para manter essa capacidade de preservar os vínculos sociais e prestar atendimento a seu público prioritário, além de permanente remodelação dos arranjos institucionais, foi necessária a introdução de uma série de inovações nos mecanismos de governança. Ressalte-se que, para o BC, o sistema de governança figura entre os elementos mais importantes para as organizações financeiras ampliarem a confiança do público e trazer novos investimentos e recursos. Entre os benefícios que a melhoria dos mecanismos de governança pode trazer para as organizações microfinanceiras em geral e particularmente para as cooperativas de crédito destacam-se os seguintes: mais segurança, aumento da participação e do controle interno, desenvolvimento da visão cooperativista, redução de custos operacionais, fortalecimento dos conselhos e maior estímulo ao desenvolvimento profissional (BANCO CENTRAL, 2008).

$\mathrm{Na}$ Cresol, as bases regionais de serviço representam o principal exemplo de inovação no modelo de governança, e que tem exercido influência direta na sua eficiência administrativa. Embora não sejam reconhecidas juridicamente pelo $\mathrm{BC}$ - pois funcionam

10 As redes cooperativas que participam da Ancosol são as seguintes: Cooperativa Central de Crédito e Economia Solidária (Ecosol); Cooperativa Central de Crédito Rural com Interação Solidária (Cresol Baser); Cooperativa de Crédito Rural de Interação Solidária (Cresol Central); Associação das Cooperativas de Apoio a Economia Familiar (Ascoob); Cooperativa de Crédito Rural dos Pequenos Agricultores e da Reforma Agrária (Crehnor). São também filiadas as cooperativas "solteiras" vinculadas aos sistemas Creditag e Integrar, já que ambos não possuem ainda sua central. 
como cooperativas centrais de serviços e não de crédito -, tais estruturas reúnem cooperativas de crédito de uma mesma área geográfica. Essas bases descentralizadas fornecem coesão e agilidade administrativa, diminuindo seus custos operacionais, aproximando suas diferentes instâncias e fortalecendo a representação das cooperativas singulares nos órgãos superiores do Sistema.

Em relação à participação social, já no segundo ano de atuação a Cresol tomou a decisão de transferir o gerenciamento das cooperativas aos agricultores que fossem eleitos dirigentes, dispensando a figura do gerente. A opção fez com que se empreendesse um esforço inusitado no campo da capacitação, visto que a grande maioria de seus associados (agricultores familiares) tinha apenas o ensino fundamental. Por outro lado, a medida revelou-se fundamental em termos de autonomia e de controle de custos administrativos, pois permitiu que centenas de lideranças, em geral jovens agricultores, assumissem cargos administrativos e o controle direto de suas próprias organizações. Com isso, na Cresol não se reproduz aquilo que Rutheford (2002, p.82) constatou ao estudar o sistema cooperativista mundial, ou seja os "pobres normalmente são sócios de cooperativas, [mas em geral essas organizações] são administradas por gente com maior nível de escolaridade da classe média" (tradução nossa).

Desde 2004, as organizações que compõem o sistema Cresol estão agrupadas em duas centrais de crédito. A primeira (Cresol Baser) tem como sede o município de Francisco Beltrão (PR) e atua nos estados do Paraná e Santa Catarina. Localizada em Chapecó (SC), a segunda (Cresol Central) foi constituída a partir do desmembramento da Baser. Sua ação abrange as cooperativas localizadas nos estados do Rio Grande do Sul e, também, de Santa Catarina. O elevado número de filiadas, a filosofia da descentralização que rege o sistema e diferenças de concepção no campo da política sindical rural foram os principais fatores que induziram à criação dessa segunda central. A atuação simultânea das duas centrais no estado de Santa Catarina foi o mecanismo encontrado pelos dirigentes para equacionar os dilemas de subdivisão das áreas geográficas de intervenção, que surgiram durante o processo de desmembramento dos dois Sistemas Cresol (BÚRIGO, 2006). 
Em dezembro de 2007, a Cooperativa Central de Crédito Cresol Baser possuía 73 singulares filiadas e 40 PAC. Tendo perto dos 60 mil associados, contava ainda com o apoio de milhares de dirigentes, centenas de agentes comunitários e quase 400 funcionários. Integrado por seis bases regionais paranaenses e duas catarinenses, suas unidades cobrem uma área de abrangência de quase 200 municípios.

Por sua vez, a Cresol Central possuía, nessa mesma data, 51 singulares, 39 PAC, 46,4 mil filiados, sendo que suas unidades abrangiam uma área de quase 300 municípios do Rio Grande do Sul e de Santa Catarina. Para dar conta da expansão, a estrutura do Sistema Cresol Central conta com o apoio de quase uma centena de dirigentes liberados, 1.250 agentes comunitários voluntários e mais de 300 funcionários. Atualmente, possui cinco bases regionais, três em Santa Catarina e duas no Rio Grande do Sul.

A Cresol Baser recebeu, recentemente, destaque no relatório anual do The Mix Market, organização que reúne dados sobre instituições de microfinanças de todo mundo. $O$ relatório, baseado em informações do ano de 2007, coloca a Cresol Baser na 21 $1^{a}$ posição no ranking das maiores instituições de microfinanças da América Latina e do Caribe. $\mathrm{O}$ crescimento do Cresol foi considerado o mais expressivo entre as trinta primeiras do ranking das maiores instituições de microfinanças - no ano anterior a Cresol aparecia na $28^{\mathrm{a}}$ posição. Além disso, ela ocupa o 6 o lugar no quesito de eficiência em operações de crédito com valores abaixo de U\$ 500 (CRESOL BASER, 2008).

Para acessar recursos de políticas públicas, os Sistemas Cresol Baser e Central mantêm acordos de cooperação com os principais bancos estatais. A partir de 2006, as duas centrais conseguiram ser enquadradas como agentes financeiros do Banco Nacional de Desenvolvimento Econômico e Social (BNDES), depois de cinco anos de tratativas. Além de permitir o acesso a todas as linhas de crédito e microcrédito do Banco - como o PNMPO -, a medida está facilitando a aplicação dos recursos do Pronaf por meio das cooperativas. Como o BNDES caracteriza-se por ser um agente financeiro de segundo piso, isto é, não opera no mercado financeiro varejista, a liberação de recursos de Pronaf para as unidades da Cresol torna-se menos burocrática sob o ponto de vista operacional e político. O repasse 
de Pronaf por intermédio do BNDES reduz, também, os problemas observados todos os anos entre algumas singulares dos Sistemas Cresol e as agências do Banco do Brasil (BB), atualmente a principal instituição oficial de gestão e operacionalização do Pronaf. Em determinadas regiões, o acirramento da concorrência no mercado financeiro local acaba criando dificuldades para a liberação pelo BB dos financiamentos de Pronaf por intermédio das cooperativas. Essas disputas locais afetam os produtores, que ficam reféns da má vontade de muitos gerentes de bancos e não podem seguir corretamente o calendário agrícola, além de prejudicar as metas de aplicação das verbas dos planos-safra estabelecidas pelo Governo Federal.

Nos últimos anos, as parcerias dos sistemas Cresol fortaleceram-se também junto à rede bancária privada, principalmente por intermédio de acordos para operar recursos do Pronaf oriundos da exigibilidade bancária ${ }^{11}$. Os primeiros acordos nesse sentido foram com os bancos Safra e Bradesco. Desde 2004, os sistemas Cresol sustentam acordos de cooperação, também, com a Caixa Econômica Federal (Caixa) e com Ministério das Cidades, para operar os projetos de crédito habitacional, que estão ligados ao Programa de Subsídio a Habitação de Interesse Social (PSH). Desde então, mais de cinco mil moradias rurais já foram construídas ou reformadas com a ajuda de financiamentos públicos intermediados pelas cooperativas.

Para ampliar os benefícios aos seus cooperados, a Cresol intensificou os acordos de cooperação na área da assistência técnica. Frequentemente, suas cooperativas desenvolvem projetos aprovados junto aos dois ministérios ligados à agricultura - Ministério do Desenvolvimento Agrário e Ministério da Agricultura, Pecuária e Abastecimento - e realizam atividades conjuntas com as empresas estaduais de extensão rural. Em algumas regiões, essas ações ganham o reforço de técnicos de prefeituras, cooperativas agropecuárias e de ONG. No âmbito da cooperação internacional, as parcerias que a Cresol Baser mantém com organizações belgas,

11 Percentual dos recursos oriundos dos depósitos a vista que os bancos são obrigados a aplicar no crédito rural. Para atender essa determinação, muitos bancos efetuam acordos repassando seus recursos para agentes financeiros que possuem carteiras de crédito rural. Outros não direcionam verbas para essa área, preferindo pagar as multas impostas pela legislação. 
alemãs e holandesas têm fortalecido suas carteiras de microcrédito e viabilizado a contratação de técnicos para atuar junto ao público rural de baixa renda. Há oito anos a Cresol Baser recebe assessoria de um banco cooperativo holandês, com destaque para a concepção de metodologias de controle e gestão, além da criação de novos produtos para atender a demanda do seu quadro social ${ }^{12}$.

$\mathrm{Na}$ atualidade, os Sistemas Cresol disponibilizam dezenas de produtos e serviços financeiros aos seus associados. Além do Pronaf, das operações de PNMPO e dos financiamentos para novas construções ou melhorias habitacionais, a modalidade de crédito denominada "Bem-estar familiar" merece destaque pelos seus resultados sociais. Essa modalidade destina-se à aquisição de móveis, utensílios, artigos e eletrônicos para uso doméstico, como também para o tratamento de saúde (consultas, medicamentos e cirurgias), compra de materiais, mensalidades escolares, viagens a turismo e atividades de lazer.

Desde que começou a operar em 1996, as aplicações de Pronaf não pararam de crescer no âmbito do Cresol. Considerado o principal programa público voltado para a agricultura familiar, a mobilização política dessa categoria social, a lógica do mutualismo que sustenta as suas organizações cooperativas e as experiências de algumas lideranças com a gestão de fundos rotativos foram elementos decisivos para que o programa se tornasse um caso de sucesso no interior dos sistemas. Esses elementos fizeram com que, desde o início, os principais líderes do Cresol encarassem o Pronaf como uma política pública de crédito, e não como uma ação paternalista de governo e, portanto, sem controle sobre o ressarcimento dos empréstimos.

Em 2007, o total de Pronaf disponibilizado pelas duas centrais foi de, aproximadamente, $\mathrm{R} \$ 273,8$ milhões. Nesse ano, na Cresol Baser, o número total de contratos de Pronaf chegou a 24,6 mil e o volume de recursos aplicados a R\$ 147,7 milhões (R\$ 102,7

12 O banco cooperativo Rabobank - Cooperatieve Raiffeisen Boerenleenbank - foi fundado em 1972, baseado nos ideais de um dos maiores precursores do cooperativismo de crédito, o alemão Friedrich Raiffeisen. O modelo concebido por Raiffeisen foi implantado, em meados do século XIX, em várias partes da Alemanha e depois reproduzido em outros países da Europa. 
milhões em custeio e R \$ 45,1 milhões em investimento). Na Cresol Central foram efetuados 24,4 mil contratos e disponibilizados R\$ 126 milhões (R\$ 98,1 milhões de custeio e R\$ 27,9 milhões de investimento). Tais números colocam o Pronaf como o principal produto disponibilizado pelos Sistemas Cresol, embora nos últimos anos sua presença venha diminuindo em termos relativos. Se em 2003, os repasses do Programa representavam em torno de $75 \%$ dos créditos concedidos, em julho de 2007 eles compunham 69,8\% da carteira total do Cresol Baser (PLANET RATING, 2004, 2008).

No campo educacional, as ações conjuntas dos sistemas Cresol são também importantes quando analisadas sob a ótica do desenvolvimento e formação de capital social. Em 2005, a Cresol Baser criou o Instituto de Formação do Cooperativismo Solidário (Infocos), pelo qual são promovidas diversas ações de capacitação que atendem diferentes níveis de formação. São oferecidas desde a formação básica para os membros de novas cooperativas até cursos à distância, que envolvem centenas de cooperados distribuídos em diversos municípios de Santa Catarina e do Paraná. Com a tutela de universidades públicas e privadas, as duas centrais Cresol promovem também cursos específicos direcionados aos dirigentes e funcionários. Alguns desses programas formativos oferecem títulos de pós-graduação ou de especialização pós-médio, dependendo do nível de escolaridade dos participantes.

Porém, a capacidade que os Sistemas Cresol vêm demonstrando em gerar inovações no campo institucional-financeiro e educacional em benefício da agricultura familiar não encontra correspondência no campo técnico-produtivo. Apesar dos dirigentes afirmarem que suas cooperativas jamais deixaram de apoiar projetos consistentes e inovadores em termos ambientais, os recursos do Pronaf Custeio continuam sendo destinados basicamente para a viabilização de sistemas produtivos considerados convencionais. Na maioria dos casos, esses recursos são aplicados para o financiamento das culturas do milho, feijão e soja e para atividades com a produção de leite, a criação de frangos e suínos. Os cultivos orgânicos, sem o uso de insumos químicos sintéticos, são ainda minoritários nas carteiras das cooperativas, o que significa que essas organizações 
têm limitações para conceber e difundir um modelo de agricultura diferenciado do sistema produtivista, que se baseia no uso intensivo de insumos agroquímicos sintéticos.

A contradição entre o discurso dos dirigentes e o que se observa nos financiamentos das cooperativas de crédito solidárias demonstra que as mudanças técnico-produtivas possuem condicionantes complexos e envolvem aspectos que estão, muitas vezes, acima da capacidade de intervenção dessas organizações. Estudando o Sistema Cresol, Junqueira (2003, p.99-100) assinala que "a estrutura de incentivos que possibilite mudanças institucionais necessárias à adoção de novas práticas produtivas deve-se incorporar aos métodos e às decisões dos formuladores de políticas e agentes econômicos. Sob este ponto de vista foge-se, em parte, da governabilidade do sistema". Percebe-se, assim, que a implantação e a condução de novos sistemas produtivos está diretamente vinculada à matriz técnica e política predominante no interior das principais redes de serviços de assistência técnica e extensão rural existentes no país. Até o momento, o desenho institucional dos serviços de extensão rural, assistência técnica e educação rural voltados à agricultura familiar não conseguiu suplantar os descompassos relacionados às suas atribuições e competências, e menos ainda com sua tradição tecnicista e difusionista.

\section{Conclusões}

A perspectiva do desenvolvimento territorial sustentável passa pela construção de novos ambientes institucionais e o fortalecimento de interdependências entre setores econômicos e entre as esferas políticas, sociais e espaciais. Dotar os territórios rurais brasileiros, por exemplo, de serviços financeiros bem estruturados e capazes de atender a demanda por crédito da parcela da população excluída do sistema bancário representa uma ação de primeira ordem nessa direção. Em outras palavras, fortalecer a lógica de desenvolvimento territorial sustentável pressupõe ampliar as possibilidades das pessoas e das organizações de manejar os instrumentos e os recursos financeiros endógenos, bem como ampliar o acesso a programas de agências externas. 
A falta de compreensão e de capacidade para operar estrategicamente nesse campo apenas demonstra a fase embrionária das instâncias de planejamento implicadas com o enfoque do desenvolvimento territorial sustentável no Brasil. Muitas delas ainda não são concebidas como arenas voltadas à reflexão crítica e à formulação de projetos criativos de interesse comum. Uma análise sobre como são concebidos e executados os projetos e como se dão as dinâmicas de decisão dos colegiados gestores permite afirmar que, em geral, seus componentes ou são afeitos ao clientelismo ou são induzidos a se comportar como "agentes da sua própria causa", preocupados, sobretudo, em garantir uma fatia de recursos públicos em disputa (CAZELLA \& BÚRIGO, 2008b e 2009). Esse perfil de gestão e a falta de proximidade das organizações financeiras envolvidas nos processos de DTS reforça o descompromisso coletivo com a viabilidade dos empreendimentos financiados.

Este estudo demonstrou que novos desafios precisam ser superados para se avançar na construção de sistemas de financiamento do desenvolvimento territorial sustentável. Em primeiro lugar, tanto as cooperativas de crédito dos Sistemas Cresol, quanto o Crediamigo não conseguiram alcançar de forma contundente os estratos mais pobres da população. $\mathrm{O}$ acesso a recursos subsidiados de programas públicos carece de contrapartidas dos agentes financeiros locais e de suas organizações de apoio no sentido de ousar na concepção e ampliação de iniciativas de inclusão econômico-produtiva e financeira "dos mais pobres entre os pobres" e de preservação ambiental. Trata-se aqui de implementar mecanismos de contratualização de políticas públicas, que se baseiem "em compromissos recíprocos entre o Estado, a Sociedade Civil e as famílias rurais e de agricultores atendidos" (CAZELLA, BONNAL \& MALUF, p.300).

Em segundo, as cooperativas afiliadas aos Sistemas Cresol caracterizam-se por uma intervenção setorial, contemplando de forma marginal as demais atividades econômicas existentes no meio rural. Soma-se a isso a fragilidade das intervenções voltadas para um estilo de desenvolvimento agrícola mais respeitoso do meioambiente. Essa falta de inovações no padrão dos financiamentos revela também as debilidades das organizações de extensão rural e assistência técnica, que não tem conseguido adequar-se às necessi- 
dades dos agricultores familiares e demais empreendedores rurais. Não somente as tentativas de criação e consolidação de cooperativas, associações e empresas de prestação de serviços têm registrado avanços pouco significativos, como a maioria dos órgãos de governo de pesquisa e extensão rural encontra-se pouco preparado para conceber e fomentar projetos inovadores no meio rural.

Os avanços e as fragilidades aqui apontados apenas reforçam a necessidade de se criar sinergias entre as políticas públicas de crédito e os agentes financiadores do desenvolvimento. Embora as experiências do Crediamigo e dos Sistemas Cresol incluam ao sistema financeiro nacional uma pequena parcela de microempreendedores e da população de baixa renda, sua solidez e resultados positivos representam um convite a dirigentes e gestores de instituições de desenvolvimento rural a conhecê-las nos seus pormenores. Os esforços de diversos agentes financeiros públicos e privados para aprofundar a bancarização dos segmentos pobres poderiam inspirar-se nas metodologias aqui assinaladas. Certamente, as tentativas de aumentar a inclusão social adotadas por esses bancos precisam ser efetuadas de maneira mais coerente com os preceitos do DTS. Tais mudanças exigem mudanças de conduta de agentes financeiros que, apesar de defenderem no discurso seu papel de responsabilidade socioambiental, na prática mantêm uma intervenção clássica e conservadora.

O fato do Crediamigo e do Cresol estarem estrategicamente localizadas nas regiões Nordeste e Sul pode representar uma possibilidade inusitada de aprendizado e transferência no interior do país de tecnologias de gestão e de participação social. A difusão do cooperativismo de crédito rural no Nordeste e Norte e a adoção dos preceitos de gestão do microcrédito pelas instituições financeiras do Sul ampliariam de forma consistente o processo de inclusão financeira de segmentos sociais de baixa renda. Tais articulações são também fundamentais para se aumentar as capacidades institucionais e a qualidade dos projetos de desenvolvimento das demais regiões brasileiras.

O cooperativismo de crédito solidário já cumpre o papel de inspirar a estruturação de sistemas financeiros semelhantes em regiões do país sem tradição nessa área. Suas características de estímulo a auto-gestão representram elementos fundamentais para a formação de capital social e de novos arranjos produtivos 
nos territórios. Porém, é importante que as estratégias de constituição de novas cooperativas sigam metodologias apropriadas de sensibilização e de capacitação técnica. O arranjo institucional a ser formado precisa envolver adequadamente os distintos segmentos sociais e as organizações existentes no território. Isso é fundamental para que a futura cooperativa de crédito não se torne apenas uma organização financeira local, mas possa desempenhar com sucesso seu papel de instrumento de apoio a um estilo de desenvolvimento sustentável do ponto de vista econômico, social e ambiental.

Recebido em 15.2.2009

Aprovado em 25.3.2009

\section{Referências}

ABRAMOVAY, R. Alcance e limites das finanças de proximidade no combate à inadimplência: o caso do agroamigo. Fipe, Texto para discussão, n ${ }^{\circ} 10$. São Paulo, 2008.

. (Org). Laços financeiros na luta contra a pobreza. São

Paulo: Ed. Annablume, 2004.

ABRAMOVAY, R. Finanças de proximidade e desenvolvimento territorial no semi-árido brasileiro. In: . O futuro das regiões rurais. Porto Alegre: Editora da UFRGS, 2003a.

ABRAMOVAY, R. et. al. Mercados do empreendedorismo de pequeno porte no Brasil. In: CEPAL. Pobreza e mercados no Brasil. Brasília: DFID, 2003b.

ANDERSON, L \& NUGENT, R. Microcredit, Social Capital, and Commom Pool Resources. World Development, [S.I.]. v. 30 n.1, 2002.

AUSTIN RATING. Disponível em: < http://www.austin.com.br>. Acesso em: 13 abr 08.

BÉDARD, G. Argent chaud et argent froid. La mobilization de l'epargne locale par des instituitions cooperatives et son impact sur le développement local. Synthèse de sept etudes de cas africains. Cahiers de l'Université Cooperative Internationale, Paris, n.7, 1986.

BITTENCOURT, G. Abrindo a caixa preta: o financiamento da agricultura familiar no Brasil. Campinas, 2003. 213 f. Dissertação 
(Mestrado em Desenvolvimento Econômico, Espaço e Meio Ambiente) - Instituto de Economia, Universidade Estadual de Campinas.

BONNAL, P. \& PIRAUX, M. Projetos coletivos de desenvolvimento territorial no entorno de Campina Grande, PB: o elo faltante da multifuncionalidade da agricultura familiar. In: CAZELLA, A. A. et al. (Org.). Agricultura familiar: multifuncionalidade e desenvolvimento territorial no Brasil. Rio de Janeiro: Ed. Mauad X, 2009.

BÚRIGO, F. L. Inclusão financeira e desenvolvimento territorial no Brasil. Brasília: Fórum DRS/IICA, 2008.

BÚRIGO, F. L . Cooperativa de crédito rural: agente de desenvolvimento local ou banco comercial de pequeno porte? Chapecó: Argos, 2007.

. Finanças e Solidariedade: uma análise do cooperativismo de crédito rural solidário no Brasil. Florianópolis, 2006. 274 f. Tese (Doutorado em Sociologia Política) - Centro de Filosofia e Ciências Humanas, Universidade Federal de Santa Catarina. Disponível em $<$ http://www.nesfi.ufsc.br $>$.

. Cooperativismo de crédito rural: lições de uma experiência. In: MONTOYA, Marco Antônio (Org.). Aspectos regionais do crédito rural: governo, cooperativas e informalidade. Passo Fundo: UPF, 2002.

CAZELLA, A. Contribuições metodológicas da sócio-antropologia ao desenvolvimento territorial sustentável. Florianópolis, Eisforia, 2006.

CAZELLA, A. \& BÚRIGO, F. Sistemas de financiamento para projetos territoriais estratégicos de natureza multisetorial. Rio de Janeiro, OPPA/CPDA/IICA, Relatório de pesquisa, 2008a.

. O desenvolvimento territorial no planalto catarinense: o difícil caminho da intersetorialidade. Revista Extensão Rural, Santa Maria, v. 15, 2008b.

. Multifuncionalidade da agricultura familiar e território: avanços e desafios para a conjunção de enfoques. In: CAZELLA, A. et. al. (Org.). Agricultura familiar: multifuncionalidade e desenvolvimento territorial no Brasil. Rio de Janeiro: Mauad X, 2009.

CAZELLA, A.; BONNAL, P. \& MALUF, R. S. Impasses do desenvolvimento territorial na serra catarinense: limitação agroecológica face $d$ 
expansão do ‘deserto verde'. In: CAZELLA, A. et. al. (Org.). Agricultura familiar: multifuncionalidade e desenvolvimento territorial no Brasil. Rio de Janeiro: Mauad X, 2009.

DARCY, S. \& SOARES, M. M. Democratização do crédito no Brasil: atuação do Banco Central. [Brasília]: Banco Central, 2004. Disponível em: <http:// www.bcb.gov.br.>. Acesso em: 21 jan. 2004.

CERISE. Disponível em: < http://www.cerise-microfinance.org/pdf/ Es/guia_gobernabilidad.pdf $>$. Acesso em: $10 \mathrm{abr} 08$.

CRESOL-BASER. Disponível em: < http://www.cresol.com.br>. Acesso em: 25 jul. 2008.

FERNANDES, S. A. Gênero e políticas de crédito: O Pronaf mulher em Santa Catarina. Florianópolis, CFH/UFSC, PPGSP, 2008 (Dissertação de Mestrado).

FERRARY, M. Trust and social Capital in the Regulation of lending Activities. Journal of Socio-Economics. n.31, 2003.

GONZALEZ VEGA, C. Uma Visão Geral das Microfinanças. In: Seminário Internacional de Microfinanças, 2000, Rio de Janeiro. Anais... Rio de Janeiro: BNDES, 2000

HIRSCHLAND, M. Conférence virtuelle sur la mobilization de l' épargne: quelques élements de conclusion. In: Espace Finance. Pôle microfinancement \& son fórum de discussion. BIM n.29, 10 set. 2002. Paris: Cirad, Gret, 2003. 1 CD-ROM

JUNQUEIRA, R. G. P. Finanças solidárias e agricultura familiar: o sistema Cresol de cooperativas de crédito rural. São Paulo, 2003. 107 f. Dissertação (Mestrado em Ciência Ambiental) - PROCAM, Universidade de São Paulo.

MAGALHÃES, R. A importância das instituições e das redes sociais no desempenho dos mercados financeiros. In: CONGRESSO BRASILEIRO DE ECONOMIA E SOCIOLOGIA RURAL, 41., 2003, Poços de Caldas. Anais... Brasília: Sober, 2003.

MORDUCH, J. The microfinance schism. World Development, [S.I.], v.28, n. 4, 2000.

. The role of subsidies in microfinance: evidence from the Grameen Bank. Journal of Development Economics, [S.I.], v. 60, 1999. 
NERI, M. C. (Coord.). Microcrédito, o mistério nordestino e o Grammem brasileiro. Rio de Janeiro, FGV/IBRE/CPS, 2008.

PLANET RATING. Sistema Cresol. Disponível em: <//http://www. planetrating.com/ratings/CRESOL_PlanetRating_040108_ES.pdf. $>$. Acesso em: 12 set. 2008.

RUTHERFORD, S. Los pobres y su dinero. Tequisquiapan, México: La Colmena Milenaria; México, DF: Universidad Iberoamericana, 2002.

SERVET, J-M; VALLAT, D (Orgs.). Exclusion et liens financiers. Rapport du Centre Walras - 2001. Paris: Economica, 2001.

SOARES, M. M.; MELO SOBRINHO, A. D. Microfinanças: o papel do Banco Central do Brasil e a importância do cooperativismo de crédito (2 ed. amp. rev.). Brasília: Banco Central do Brasil, 2008. Disponível em: <http://www.bcb.gov.br>.

STIGLITZ, J. E. El rumbo de las reformas: hacia una nueva agenda para a América Latina. Revista de la Cepal 80. [Santiago], p.7-40, ago. 2003.

YUNUS, M. Expanding microcredit outreach to reach the millenium development goal: some issues for attention. (Paper presented at the International Seminar on Attacking Poverty with Microcredit, Dhaka, jan. 2003).

YUNUS, M; JOLIS, A. O banqueiro dos pobres. São Paulo: Ed. Ática, 6ae ed., 2003.

\section{Abstract \\ Financial inclusion and rural development: the importance of territorial organizations}

In this article we analyze conditions for the construction of systems for financing processes of sustainable land development in rural áreas. In particular, we look at possibilities and dilemmas surrounding the financial inclusion of impoverished social segments and for increasing the participation of territorial organizations in the management of these systems. Based on these two issues, our work looks at empirical experiences that demonstrate progress made in this direction: the Crediamigo Program of the Banco do Nordeste and the cooperativism of the "solidarity" credit form that has sprung up in Brazil's southern region. We conclude that both 
cases present innovative institutional arrangements that have generated results that have had a relevant impact on the volume of loans, the area that they reach out to and cover, the percentage of the population attended and systems of governing. Nonetheless, both must perfect their forms of action if they are to attend to intersectorial demands thatfocus on the development of the lands within which they are at work.

Keywords: sustainable land development, financial inclusion, governing systems. 
